\title{
KAJIAN KEINJEKTIFAN MODUL (MODUL INJEKTIF, MODUL INJEKTIF LEMAH, MODUL MININJEKTIF)
}

\author{
Baidowi $^{1}$, Yunita Septriana Anwar ${ }^{2}$ \\ ${ }^{1}$ Program Studi Pendidikan Matematika FKIP Universitas Mataram \\ ${ }^{2}$ Jurusan PMIPA FKIP Universitas Muhammadiyah Mataram \\ Email: baidowiunram@gmail.com
}

\begin{abstract}
Abstrak. Diberikan $M$ adalah $R$-modul. Modul $M$ dikatakan injektif jika untuk setiap monomorfisma $\phi: M \rightarrow$ $N$ dan setiap homomorfisma $\psi: M \rightarrow Q$ terdapat homomorfisma $h: N \rightarrow Q$ sedemikian hingga $\psi=h \phi$. Modul $M$ dikatakan injektif-lemah jika $M$ adalah $N$-injektif lemah untuk setiap modul $N$ yang dibangun berhingga. Sedangkan $M$ dikatakan mininjektif jika untuk setiap homomorfisma dari $f: K \rightarrow Q$ dengan $K$ ideal sederhana dari $R$, terdapat homomorfisma $\varphi: R \rightarrow Q$ sedemikian hingga $f=\varphi i$. Kajian keinjektifan dalam tulisan ini meliputi modul injektif, modul injektif-lemah, dan modul mininjektif yang mengkaji karakterisasi dari masingmasing modul. Khusunya ketiganya memiliki karakterisasi yang khusus pada jumlahan tak berhingganya.
\end{abstract}

Kata Kunci : Modul injektif, modul injektif-lemah, modul mininjektif

\begin{abstract}
Let $M$ be an $R$-module. An $R$-module $M$ is called injective if for any monomrphism $\phi: M \rightarrow N$ and for any homomorphism $\psi: M \rightarrow Q$ there exists a homomorphism $h: N \rightarrow Q$ such that $\psi=h \phi$. We say that an $R$-module $M$ is weakly-injective if $M$ is weakly $N$-injective for every finitely generated module $N$. An $R$-module $M$ is called mininjective if every homomorphism $f: K \rightarrow Q$, there exists a homomorphism $\varphi: R \rightarrow Q$ such that $f=\varphi i$, with $K$ is simple ideal of $R$. In this paper, we give some characterizations and properties of injective modules, weakly-injective modules, and mininjective modules. In particular, they have different characterizations for their infinite direct sum.
\end{abstract}

Keywords : Injective modules, weakly-injective modules, mininjective modules

\section{PENDAHULUAN}

Modul injektif pertama kali muncul dalam konteks grup Abelian. L. Zippin meneliti di tahun 1935 bahwa grup Abelian disebut injektif jika dan hanya jika grup Abelian tersebut merupakan penjumlah langsung dari sebarang grup yang memuatnya sebagai subgrup. Perumuman dari modul injektif atas sebarang ring pertama kali diteliti oleh $\mathrm{R}$. Baer dalam paper Abelian groups that are direct summand of every containing Abelian group. Baer bekerja dengan apa yang disebutnya modul lengkap (complete module) atas ring $R$. Baer membuktikan bahwa suatu modul dikatakan lengkap jika dan hanya jika modul tersebut merupakan penjumlah langsung dari setiap modul yang memuatnya. Modul lengkap inilah yang kemudian disebut modul injektif.

Modul $M$ disebut relatif injektif terhadap modul $N$ atau $N$-injektif, jika untuk setiap monomorfisma $\beta: X \rightarrow N$ dan setiap homomorfisma $\psi: X \rightarrow M$ terdapat homomorfisma $\sigma: N \rightarrow M$ sedemikian hingga $\psi=\sigma \beta$. Modul $M$ disebut modul injektif jika $M$ adalah $R$-injektif. Sebarang jumlahan berhingga dari keluarga $R$-modul injektif juga merupakan modul injektif tetapi tidak berlaku untuk jumlahan tak berhingganya. H. Bass dan Z. Papp mengkaji bahwa jumalahan tak berhingga keluarga $R$ modul injektif juga merupakan modul injektif asalkan $R$ adalah ring Noetherian.
Modul $M$ dikatakan relatif injektif lemah terhadap modul $N$ atau $N$-injektif lemah jika untuk setiap homomorfisma $\psi: N \rightarrow E(M)$ berlaku $\psi(N) \subset X \cong M$ untuk setiap submodul $X$ dari $E(M)$. Sedangkan modul $M$ dikatakan injektif-lemah jika $M$ merupakan modul $N$-injektif lemah untuk setiap modul $N$ yang dibangun berhingga. Modul injektiflemah tertutup terhadap jumlahan langsung berhingga dan perluasan esensialnya, tetapi terhadap penjumlah langsungnya modul injektif-lemah tidak bersifat tertutup. Begitu juga untuk jumlahan langsung sebanyak tak berhingga dari modul injektif-lemah belum tentu kembali menjadi modul injektiflemah.Dalam Teorema 3 dinyatakan bahwa untuk $R$ ring q.f.d, maka jumlahan langsung sebanyak tak berhingga R-modul injektif-lemah adalah modul injektif-lemah.

Modul $M$ disebut modul mininjektif jika untuk setiap homomorfisma dari $f: K \rightarrow M$ dengan $K$ ideal sederhana dari $R$, terdapat homomorfisma $\varphi: R \rightarrow$ $M$ sedemikian hingga $f=\varphi i$. Setiap modul injektif adalah modul mininjektif. Yang menarik dari karakterisasi modul mininjektif adalah bahwa jumlahan tak berhingga keluarga modul mininjektif juga merupakan modul mininjektif untuk sebarang $\operatorname{ring} R$.

Dalam tulisan ini diasumsikan bahwa $R$ adalah ring asosiatif dengan elemen identitas dan semua $R$ modul kanan unital. Misalkan $R \operatorname{ring}, M$ dan $N$ adalah 
$R$-modul. Submodul $K$ dari dari $R$-modul $M$ disebut esensial di $M$, jika untuk setiap submodul tak nol $L \subset$ Mberlaku $K \cap L \neq 0$. Modul $M$ disebut perluasan esensial dari $K$ dan dinyatakan dengan $K \unlhd M$. Lebih lanjut, monomorfisma $f: L \rightarrow M$ disebut esensial jika Im $f$ merupakan submodul esensial di $M$. Notasi $N \subset^{e s s} M, N \subset^{\oplus} M$, dan $E(N)$ berturut-turut berarti $N$ submodul esensial dari $M, N$ jumlahan langsung dari $M$, dan amplop injektif dari $N$. Karakterisasi dari modul injektif diambil dari [1], [2], [3], [4], karakterisasi modul injektif lemahdiambil dari [5], [6], sedangkan karakterisasi modul mininjektif diambil dari [7], [8].

\section{PEMBAHASAN}

\subsection{Modul Injektif}

Modul injektif secara formal merupakan dual dari modul proyektif. Dualitas yang dimaksudkan adalah dengan membalik semua arah panah pada pemetaan dalam modul proyektifdan menukar epimorpisma dengan monomorphisma. Suatu $R$ modulQ disebut injektif jika untuk setiap barisan eksak pendek $0 \rightarrow L \rightarrow M \rightarrow N \rightarrow 0$ dengan $L, \quad M$, $N$ adalah $R$-modul, maka kontravariant fungtor $\operatorname{Hom}(-, Q)$ eksak kanan. Definisi modul injektif dapat juga dinyatakan dalam diagram komutatif berikut.

Definisi 1. Suatu $R$-modul $Q$ disebut modul injektif jika untuk setiap monomorfisma $\varphi: M \rightarrow N$ dan setiap homomorfisma $\quad \psi: M \rightarrow Q \quad$ terdapat homomorfisma $h: N \rightarrow Q$ sedemikian hingga diagram berikut komutatif,

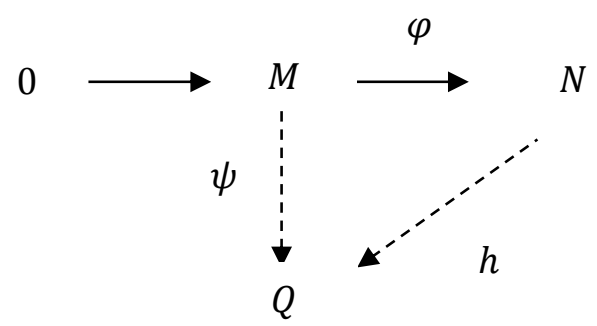

yaitu $\psi=h \varphi$.

Himpunan bilangan rasional $\mathbb{Q}$ sebagai $\mathbb{Z}$ modul merupakan salah satu contoh dari modul injektif.Modul $U$ dikatakan relatif injektif terhadap modul $M$ atau $M$-injektif jika untuk setiap monomorfisma $f: K \rightarrow M$ dan setiap homomorfisma $g: K \rightarrow U$, terdapat homomorfisma $h: M \rightarrow U$ sedemikian hingga diagram berikut komutatif:

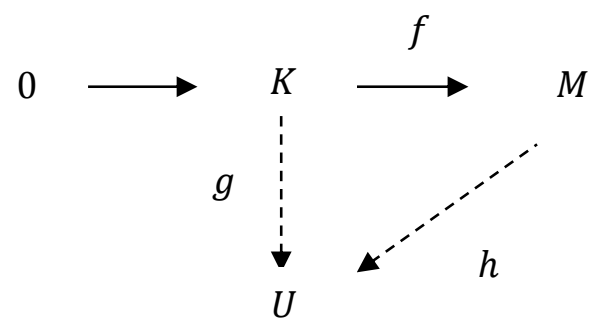

yaitu $h f=g$.

Sifat-sifat dari modul injektif dan $M$-injektif dapat dirujuk pada [1], [2], [4], dan [8]. Hasil kali langsung atau jumlahan berhingga dari keluarga modul injektif juga merupakan modul injektif seperti yang dinyatakan dalam teorema berikut.

Teorema 1. Hasil kali langsung (direct product) $Q=$ $\prod_{\alpha \in I} Q_{\alpha}$ dari modul-modul injektif $Q_{\alpha}$ adalah modul injektif jika dan hanya jika setiap $Q_{\alpha}$ adalah modul injektif.

Bukti. Misalkan $Q=\prod_{\alpha \in I} Q_{\alpha}$ adalah modul injektif dan $f_{\alpha}: M \rightarrow Q_{\alpha}$ adalah sebarang homomorfisma. Karena $Q$ adalah hasil kali langsung modul-modul injektif, maka untuk setiap $\alpha \in I$ terdapat inklusi $i_{\alpha}$ : $Q_{\alpha} \rightarrow Q$ dan proyeksi $\pi_{\alpha}: Q \rightarrow Q_{\alpha}$ sedemikian hingga $\pi_{\alpha} i_{\alpha}=1_{Q_{\alpha}}$. Perhatikan diagram berikut:

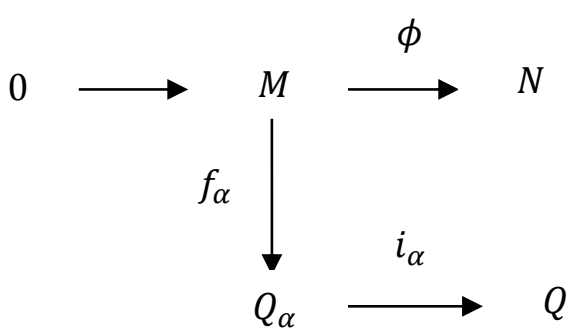

dengan $0 \rightarrow M \rightarrow N$ adalah barisan eksak pendek. Karena $Q$ modul injektif, terdapat homomorfisma $h_{\alpha}$ : $N \rightarrow Q$ sedemikian hingga $h_{\alpha} \phi=i_{\alpha} f_{\alpha}$. Didefinisikan $\psi_{\alpha}: N \rightarrow Q_{\alpha}$ sebagai $\psi_{\alpha}=\pi_{\alpha} h_{\alpha}$. Karena $\pi_{\alpha} i_{\alpha}=$ $1_{Q_{\alpha}}$, diperoleh $\psi_{\alpha} \phi=\pi_{\alpha} h_{\alpha} \phi=\pi_{\alpha} i_{\alpha} f_{\alpha}=f_{\alpha}$, yaitu diagram berikut komutatif.

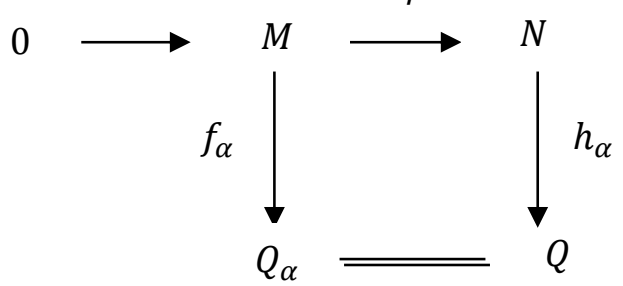

sehingga $Q_{\alpha}$ adalah modul injektif. Sebaliknya, misalkan $Q=\prod_{\alpha \in I} Q_{\alpha}$. Misalkan setiap modul $Q_{\alpha}$ adalah modul injektif. Perhatikan diagram berikut dimana $0 \rightarrow M \rightarrow N$ adalah barisan eksak pendek.

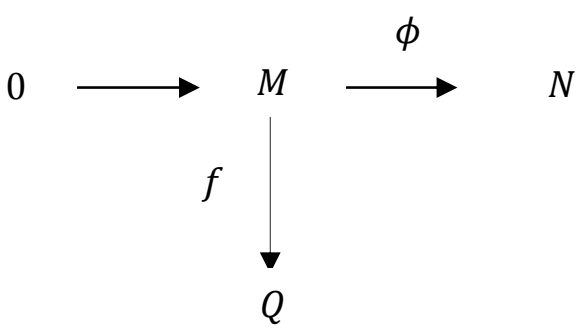

Untuk setiap $\alpha \in I$, terdapat inklusi $i_{\alpha}: Q_{\alpha} \rightarrow Q$ dan proyeksi $\pi_{\alpha}: Q \rightarrow Q_{\alpha}$. Sehingga dapat dibentuk homomorfisma $\pi_{\alpha} f: M \rightarrow Q_{\alpha}$. Mengingat $Q_{\alpha}$ adalah 
modul injektif, terdapat homomorfisma $h_{\alpha}: N \rightarrow Q_{\alpha}$ sedemikian hingga $h_{\alpha} \phi=\pi_{\alpha} f$. Didefinisikan homomorfisma $h: N \rightarrow Q$ sebagai $h(x)=$ $\left\{h_{\alpha}(x)\right\}_{\alpha \in I}$ untuk setiapn $\in N$. Tinggal ditunjukkan diagram berikutkomutatif.Perhatikan bahwa $h \phi(x)=$ $\left\{h_{\alpha} \phi(x)\right\}_{\alpha \in I}$. Akibatnya $f=h \phi$ dan $O$ adalah modul injektif.

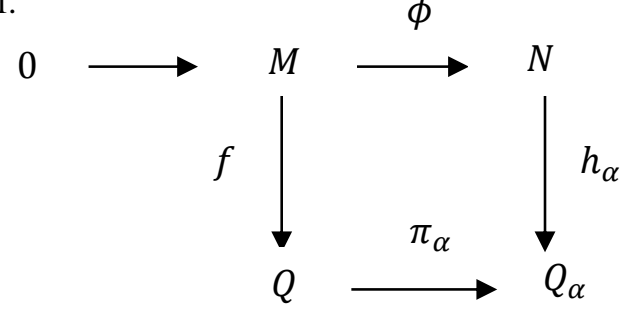

Dari Teorema 1 diperoleh bahwa jumlah langsung yang berhingga dari modul-modul injektif juga merupakan modul injektif. Tetapi secara umum untuk jumlahan langsung tak berhingga modul-modul injektif belum tentu merupakan modul injektif. $\mathrm{H}$. Bass dalam Injective dimension in Noetherianrings dan Z. Papp dalam On algebraically closed modules mengkaji bahwa jumalahan tak berhingga keluarga $R$ modul injektif juga merupakan modul injektif asalkan $R$ adalah ring Noetherian seperti yang dinyatakan teorema berikut.

Teorema 2. Suatu ring $R$ merupakan ring Noetherian jika dan hanya jika setiap jumlahan langsung dari modul-modul injektif atas $R$ adalah modul injektif.

Bukti. Misalkan $R$ adalah ring Noetherian dan $I$ adalah ideal kanan di $R$. Mengingat setiap ideal dari ring Noetherian dibangun berhingga, maka $I$ dibangun berhingga, yaitu terdapat himpunan berhingga $\left\{x_{1}, x_{2}, \cdots, x_{n}\right\}$ generator-generator $I$. Sehingga setiap $x \in I$ dapat dinyatakan sebagai $x=\sum_{i=1}^{n} x_{i} a_{i}$. Misalkan $Q=\oplus_{j \in J} Q_{j}$, dimana $Q_{j}$ adalah $R$-modul injektif. Dibentuk homomorfisma $\varphi: I \rightarrow Q=$ $\bigoplus_{j \in J} Q_{j}$. Untuk setiap generator $x_{i}$ di $I$ terdapat hanya sebanyak berhingga $j$ sedemikian hingga $\varphi\left(x_{i}\right)$ memiliki komponen ke-j tidak sama dengan nol. Karena hanya terdapat sebanyak berhingga $x_{i}$, maka terdapat subset $I_{0}$ dari $J$ sedemikian hingga $\bigoplus_{j \in I_{0}} Q_{j} \subset \bigoplus_{j \in J} Q_{j}$. Dilain pihak, karena $\bigoplus_{j \in I_{0}} Q_{j}$ adalah modul injektif, maka untuk sebarang diagram

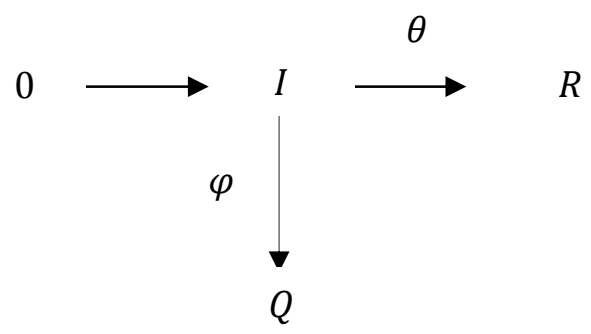

dapat dibentuk diagram komutatif

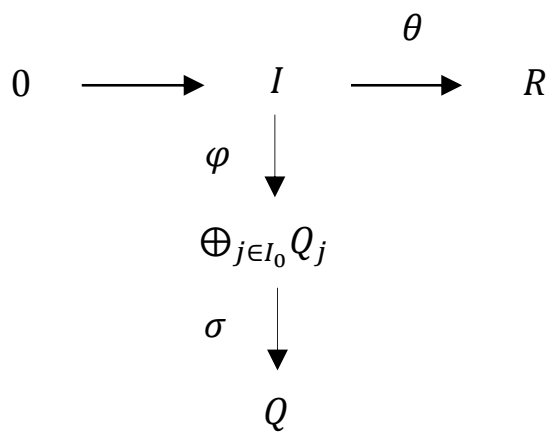

dengan $\sigma$ adalah inklusi dan $g \theta=\varphi$ dimana $g: R \rightarrow$ $\bigoplus_{j \in I_{0}} Q_{j}$. Dengan memisalkan $g^{\prime}=\sigma g$ diperoleh $Q$ adalah modul injektif. Sebaliknya, misalkan $Q=$ $\bigoplus_{j \in J} Q_{j}$ adalah modul injektif dengan setiap $Q_{j}$ adalah $R$-modul injektif. Andaikan $R$ bukan ring Noetherian. Maka terdapat tak berhingga rantai naik dari idelideal: $I_{1} \subset I_{2} \subset \cdots \subset I_{n} \subset \cdots$. Misalkan $I=U I_{n}$. Karena setiap modul merupakan submodul dari suatu modul injektif (Teorema Baer), maka untuk sebarang $n$ terdapat modul injektif $Q_{n}$ sedemikian hingga barisan $0 \rightarrow I / I_{n} \rightarrow Q_{n}$ eksak. Didefinisikan $\varphi: I \rightarrow$ $Q$ dengan $\varphi(x)=\bigoplus \varphi_{n}\left(x+I_{n}\right)$ untuk setiap $x \in I$. Mengingat $I=\bigcup I_{n}$, untuk setiap $x \in I$ terdapat $n$ sedemikian hingga $x \in I_{n}$. Akibatnya $\varphi_{n}\left(x+I_{n}\right)=0$ untuk sebanyak berhingga $n$. Sehingga $\varphi(x) \in$ $\bigoplus_{n \in S} \varphi_{n}\left(x+I_{n}\right)=Q^{\prime}$, dimana $S$ adalah himpunan berhingga. Sehingga $Q^{\prime}$ adalah modul injektif. Oleh sebab itu, terdapat homomorfisma $g: R \rightarrow$ $Q^{\prime}$ sedemikian hingga diagram berikut

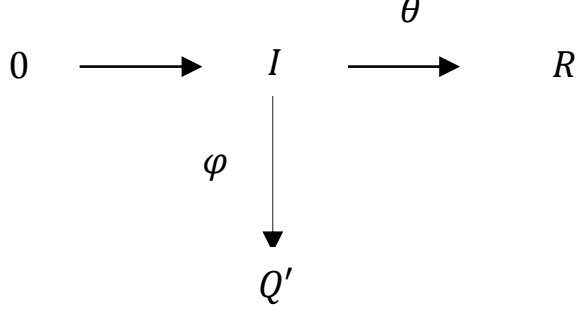

komutatif. Dalam kasus ini $\varphi_{n}\left(x+I_{n}\right)=g_{n}(x)=$ $x g_{n}(1)$ dengan $g(x)=\oplus g_{n}(x)$. Tetapi $\varphi_{n}(x+$ $\left.I_{n}\right)=g_{n}(x)=x g_{n}(1) \quad$ untuk $\quad \operatorname{setiap} x \in I_{n}$. Ini berakibat $g_{n}(1) \neq 0$ untuk setiap $n \in S$. Sehingga $g(1) \notin I_{n}$. Timbul kontradiksi, sehingga haruslah $R$ adalah ring Noetherian.

\subsection{Modul Injektif Lemah}

Diberikan $M$ dan $N$ adalah $R$-modul. Modul $M$ disebut modul $N$-injektif lemah jika untuk setiap homomorfisma $\varphi: N \rightarrow E(M)$ terdapat submodul $X \subset E(M)$ yang isomorfis dengan $M$ sedemikian hingga $\varphi(N) \subset X$. Jika modul $M$ adalah $N$-injektif lemah untuk setiap modul $N$ yang dibangun berhingga, modul $M$ dikatakan injektif-lemah. Modul $M$ disebut modul injektif-lemah sendiri jika $M$ adalah $M$-injektif lemah. Dengan cara yang sama, $R$-modul $M$ disebut $R^{n}$-injektif lemah jika dan hanya jika untuk setiap $x_{1}, x_{2}, \ldots, x_{n} \in E(M)$ terdapat 
submodul $X \operatorname{dari} E(M)$ sedemikian $\operatorname{hinggax}_{i} \in X \simeq M$, $i=1,2, \ldots, n$.Definisi dari modul $N$-injektif lemah dapat juga dinyatakan dalam diagram komutatif seperti pada lemma berikut.

Lemma1.Modul $M$ adalah $N$-injektif lemah jika dan hanya jika untuk setiap homomorfisma $\varphi: N \rightarrow$ $E(M)$, terdapat monomorfisma $\sigma: M \rightarrow E(M)$ dan homomorfisma $\hat{\sigma}: N \rightarrow M$ sedemikian hingga diagram berikut komutatif,

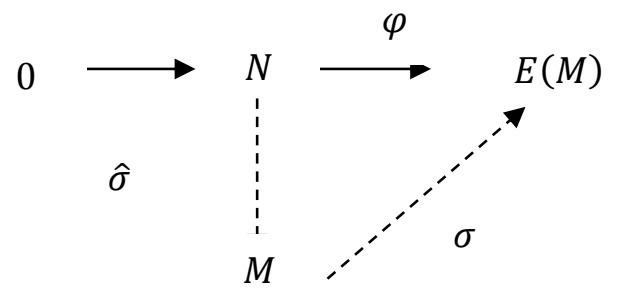

yaitu $\sigma \hat{\sigma}=\varphi$.

Suatu modul $M$ dikatakan $N$-injektif lemah jika dan hanya jika $M$ juga $K$-injektif lemah untuk setiap submodul $K$ dari $N$. Ini juga ekuivalen dengan $M$ adalah $N / K$-injektif lemah seperti yang dinyatakan dalam lemma berikut.

Lemma2. Misalkan $M$ dan $N$ adalah $R$-modul. Pernyatan berikut ekuivalen:

(i) modul $M$ adalah $N$-injektif lemah;

(ii) modul $M$ adalah $N / K$-injektif lemah untuk setiap $K \subset N$; dan

(iii) untuk setiap monomorfisma $\varphi: N / K \rightarrow E(M)$ terdapat monomorfisma $\sigma: M \rightarrow E(M)$ dan $\hat{h}: N / K \rightarrow M$ sedemikian hingga $\varphi=\sigma \hat{h}$, untuk setiap submodul $K$ dari $N$.

Lemma berikut menyatakan sifat relatif injektif-lemah tertutup terhadap jumlahan berhingga dan perluasan esensialnya.

Lemma3. Diberikan $M, N$, dan L adalah $R$-modul.

(i) Jika $L$ dan $M$ adalah modul $N$-injektif lemah, maka $L \oplus M$ adalah $N$-injektif lemah.

(ii) Jika $M$ adalah $N$-injektif lemah dan $L$ perluasan esensial dari $M$, maka L adalah $N$ injektif lemah.

Bukti.

(i) Diberikan $L$ dan $M$ adalah modul $N$-injektif lemah. Akan ditunjukkan $L \oplus M$ adalah $N$ injektif lemah. Misalkan $\varphi: N \rightarrow E(L \oplus M)$ adalah sebarang homomorfisma. Karena $L$ modul $N$-injektif lemah, maka untuk setiap $\varphi_{1}: N \rightarrow E(L)$ terdapat submodul $X_{1} \subset E(L)$ sedemikian hingga $\varphi_{1}(N) \subset X_{1} \simeq L$. Dengan cara yang sama, karena $M$ modul $N$-injektif lemah, maka untuk setiap homomorfisma $\varphi_{2}$ : $N \rightarrow E(M)$ terdapat submodul $X_{2} \subset E(M)$ sedemikian hingga $\varphi_{2}(N) \subset X_{2} \simeq M$. Didefinisikan $\quad \varphi: N \rightarrow E(L \oplus M)$ sebagai $\varphi(N)=\varphi_{1}(N)+\varphi_{2}(N)$. Pilih $X=X_{1} \oplus X_{2}$, sehingga $\quad \varphi(N)=\varphi_{1}(N)+\varphi_{2}(N) \subset$ $X_{1} \oplus X_{2} \subset X$. Jadi $L \oplus M$ adalah $N$-injektiflemah.

(ii) Diberikan $M$ modul $N$-injektif lemah dan $L$ perluasan essensial dari $M$. Akan ditunjukkan $L$ modul $N$-injektif lemah. Misalkan $\sigma: N \rightarrow$ $E(L)$ sebarang homomorfisma. Karena $M$ modul $N$-injektif lemah, maka untuk setiap homomorfisma $\varphi: N \rightarrow E(M)$, terdapat submodul $X \subset E(M)$ yang isomorfis dengan $M$ sedemikian hingga $\varphi(N) \subset X$. Mengingat $L \unlhd M$, maka $E(L) \simeq E(M)$. Sehingga $\sigma(N) \subset E(M)=E(L) \subset X$.

Jadi $M$ modul $L$-injektif-lemah.

Suatu $R$-modul $M$ disebut modul seragam jika untuk setiap dua submodul taknol di $M$ beririsan tidak trivial. Ini ekuivalen dengan mengatakan setiap submodul di $M$ merupakan submodul esensial. Suatu $R$-modul $M$ dikatakan memiliki dimensi seragam $n \in$ $\mathbb{Z}$ (ditulis $n . \operatorname{dim} M=n$ ) jika terdapat submodul esensial $V \subseteq$ ess $M$ yang merupakan jumlahan langsung sebanyak $n$ dari submodul-submodul seragam. Jika tidak terdapat bilangan bulat $n$ yang bersifat demikian dikatakan $n \cdot \operatorname{dim} M=\infty$. Untuk sebarang modul $M, n \cdot \operatorname{dim} M=0$ jika dan hanya jika $M=0$. Begitu juga, $n \cdot \operatorname{dim} M=1$ jika dan hanya $M$ adalah modul seragam.

Suatu $R$-modul $M$ disebut relatif rapat (tight)keR-modulNjika untuk setiap modul faktorN/ $K$ dari $N$ dapat disisipkan $\operatorname{di} E(M), N / K$ juga dapat disisipkan di $M$ (dapat dengan penyisipan yang berbeda). Modul $M$ dikatakan rapat jika $M$ adalah $N$ rapat untuk setiap modul $N$ yang dibangun berhingga. Hubungan antara relatif rapat dan relati injektif-lemah menjadi ekuivalen untuk setiap modul seragam seperti yang dinyatakan dalam lemma berikut.

Lemma 4. Untuk setiap modul seragam $M$, modul $M$ adalah $N$-injektif lemah jika dan hanya jika $M$ adalah $N$-rapat.

Jumlahan langsung sebanyak tak berhingga dari modul injektif lemah (rapat) belum tentu menjadi modul injektif lemah (rapat). Tetapi jika ring $R$ merupakan ring q.f.d, jumlahan langsung sebanyak berhingga dari modul injektif-lemah (rapat) juga merupakan modul injektif-lemah (rapat). Sebelumnya diberikan dahulu definisi mengenai ring q.f.d.

Definisi 2. Ring $R$ disebut ring q.f.d jika dan hanya jika untuk setiap $R$-modul siklik memiliki dimensi seragam yang berhingga (Goldie). Ini ekuivalen dengan mengatakan setiap $R$-modul siklik atau setiap $R$-modul yang dibangun berhingga memiliki socle yang dibangun berhingga yang mungkinkan sama dengan nol.

Lebih lanjut, ring $R$ disebut q.f.d jika dan hanya jika setiap $R$-modul yang dibangun berhingga 
memiliki dimensi seragam yang berhingga. Teorema berikut menjamin jumlahan langsung dari $R$-modul injektif lemah juga kembali menjadi modul injektif lemah asalkan ring $R$ merupakan ring q.f.d.

Teorema. Untuk ring kanan $R$, kondisi berikut ekuivalen:

(i) ring $R$ adalah ring q.f.d kanan;

(ii) setiap jumlah langsung dari $R$-modul injektif adalah modul injektif-lemah;

(iii) setiap jumlah langsung dari $R$-modul injektif lemah adalah modul injektif-lemah;

(iv) setiap jumlah langsung dari $R$-modul injektif lemah adalah $R$-injektif lemah;

(v) setiap jumlah langsung dari $R$-modul injektif yang tidak dapat dikomposisikan adalah $R$ injektif lemah.

Bukti. Ditunjukkan dahulu (1) $\Rightarrow(2)$. Misalkan $M=$ $\bigoplus_{i \in \wedge} E_{i}$, dimana untuk setiap $i \in \Lambda, E_{i}$ adalah $R$-modul injektif. Misalkan $N$ adalah submodul $E(M)$ yang dibangun berhingga. Karena $R$ adalah ring q.f.d, maka $N$ memuat jumlahan langsung dari submodul-submodul seragam $U_{1} \oplus \ldots \oplus U_{k}$ sebagai submodul esensialnya. Karena $M \subset^{e s s} E(M)$, maka terdapat $0 \neq q_{i} \in U_{i} \cap M$. Sehingga, $\bigoplus_{i=1}^{k} q_{i} R$ termuat di dalam jumlah langsung berhingga $\quad E_{i_{1}} \oplus \ldots \oplus E_{i_{t}}$ dari $M$, dimana $j=$ $1, \ldots, t, i_{j} \in \wedge$. Karena jumalahan langsung berhingga dari $R$-modul injektif juga merupakan $R$-modul injektif, diperoleh $\quad E_{i_{1}} \oplus \ldots \oplus E_{i_{t}}$ juga $R$-modul injektif. Mengingat bahwa amplop injektif suatu $R$-modul merupakan $R$-modul injektif minimal yang memuat suatu $R$-modul, ini berakibat $E_{i_{1}} \oplus \ldots \oplus E_{i_{t}} \quad$ memuat amplop injektif $E$ dari $\oplus_{i=1}^{k} q_{i} R$. Selanjutnya, karena $E$ adalah modul injektif dan termuat di $M$, maka $M$ dapat dinyatakan sebagai $M=E \oplus K$, untuk suatu submodul $K$ dari $M$. Misalkan $E(N)$ amplop injektif dari $N$ di dalam $E(M)$. Sehingga $E(N)=\bigoplus_{i=1}^{k} E\left(U_{i}\right)=$ $\oplus_{i=1}^{k} E\left(q_{i} R\right) \simeq E$. Karena $\bigoplus_{i=1}^{k} q_{i} R \subset^{e s s} E(N)$, sehingga $E(N) \cap K=0$. Selanjutnya, misalkan $X=E(N) \oplus K \simeq$ $E \oplus K=M$. Diperoleh $N \subset X$. Jadi $M$ adalah $R$-modul injektif-lemah. Kondisi (2) berakibat langsung pada kondisi (5). Selanjutnya, ditunjukkan (5) $\Longrightarrow$ (1). Misalkan $R / I$ adalah modul siklik. Jika $\operatorname{Soc}(R / I)=0$ bukti selesai. Andaikan bahwa $M=\operatorname{Soc}(R / I) \neq 0$. Misalkan $M=\bigoplus_{i \in \Lambda} S_{i}$ dengan $S_{i}$ dari $R$-modul sederhana. Akan ditunjukkan $M$ dibangun berhingga. Perhatikan bahwa :

$$
E(M)=E\left(\oplus_{i \in \Lambda} S_{i}\right)=E\left(\oplus_{i \in \Lambda} E\left(S_{i}\right)\right) .
$$

Misalkan $\hat{E}=E\left(\oplus_{i \in \wedge} E\left(S_{i}\right)\right)$. Karena sebarang modul sederhana merupakan modul yang tidak dapat didekomposisikan, dari hipotesis yang diberikan diperoleh jumlahan langsung dari modul sederhana $\hat{E}=$ $E\left(\oplus_{i \in \Lambda} E\left(S_{i}\right)\right)$ merupakan modul $R$-injektif lemah. Dari Lemma 2 (ii) diperoleh bahwa $\hat{E}=E\left(\oplus_{i \in \Lambda} E\left(S_{i}\right)\right)$ merupakan $R / I$-injektif lemah. Perhatikan diagram berikut.

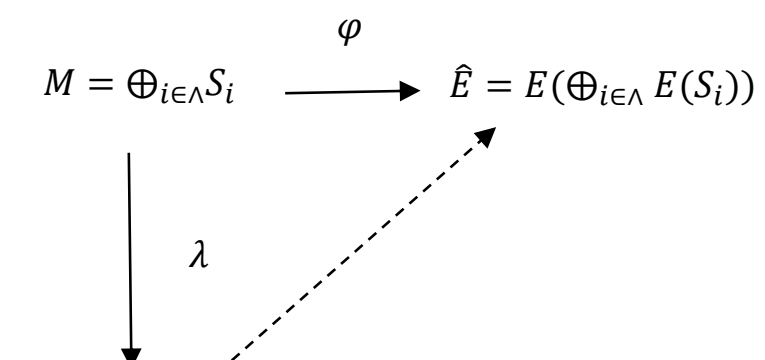

dimana $\varphi$ dan $\lambda$ adalah inklusi. Dari sifat injektif di $\hat{E}$, terdapat homomorfisma $\hat{\varphi}: R / I \rightarrow \widehat{E}=E\left(\oplus_{i \in \Lambda} E\left(S_{i}\right)\right)$ sedemikian hingga $\hat{\varphi} \lambda=\varphi$. Lebih lanjut, karena $\hat{E}=$ $E\left(\oplus_{i \in \Lambda} E\left(S_{i}\right)\right)$ merupakan $R / I$-injektif lemah, terdapat submodul $X \subset \hat{E}$ sedemikian hingga $\hat{\varphi}(1+I) \in X \cong$ $\bigoplus_{i \in \Lambda} E\left(S_{i}\right)$. Akibatnya, terdapat subset berhingga $\Gamma$ dari $\Lambda$ dan keluarga submodul-submodul yang saling lepas $\left\{X_{i}\right\}_{i \in \Gamma}$ sedemikian hingga $\hat{\varphi}(1+I) \in \bigoplus_{i \in \Gamma} X_{i}$ dan $X_{i} \cong$ $E\left(S_{i}\right)$ untuk setiap $i \in \Gamma$. Begitu juga, $M=\varphi(M) \subset$ $\hat{\varphi}(R / I)=\hat{\varphi}(1+I) R \subset \bigoplus_{i \in \Gamma} X_{i}$. Mengingat setiap $X_{i}$ adalah modul seragam, maka $M$ memuat berhingga dimensi seragam. Akibatnya, $M$ dibangun berhingga. Dengan demikian $R$ adalah ring q.f.d.

Selanjutnya ditunjukkan (2) $\Longrightarrow$ (3). Misalkan $M=$ $\bigoplus_{i \in \Lambda} M_{i}$, dimana $M_{i}$ merupakan modul injektif lemah untuk setiap $i \in \Lambda$. Misalkan $N$ adalah submodul dari $E(M)$ yang dibangun berhingga. Dari asumsi yang diberikan, jumlahan langsung dari $\bigoplus_{i \in \Lambda} E\left(M_{i}\right)$ juga modul injektif lemah. Selanjutnya,

$$
M \subset^{e s s} \bigoplus_{i \in \Lambda} E\left(M_{i}\right) \subset^{e s s} E(M) .
$$

Mengingat $\bigoplus_{i \in \Lambda} E\left(M_{i}\right)$ merupakan modul injektif lemah, terdapat submodul $Y \subset E(M)$ sedemikian hingga $N \subset Y$ dan $Y \cong \bigoplus_{i \in \Lambda} E\left(M_{i}\right)$. Misalkan $Y=\bigoplus_{i \in \Lambda} E\left(Y_{i}\right)$ sedemikian hingga $M_{i} \cong Y_{i}$ untuk setiap $i \in \Lambda$. Karena $N$ submodul $E(M)$ yang dibangun berhingga, terdapat subset berhingga $\Gamma \subset \Lambda$ sedemikian hingga $N \subset$ $\oplus_{i \in \Gamma} E\left(Y_{i}\right)=E\left(\oplus_{i \in \Gamma} Y_{i}\right)$. Karena setiap $Y_{i}$ merupakan modul injektif lemah, jumlahan berhingga $\bigoplus_{i \in \Gamma} Y_{i}$ juga merupakan modul injektif lemah. Sehingga, terdapat $X_{1} \cong \bigoplus_{i \in \Gamma} Y_{i} \cong \bigoplus_{i \in \Gamma} M_{i}$ sedemikian hingga $N \subset X_{1} \subset$ $E\left(\oplus_{i \in \Gamma} Y_{i}\right)$. Tetapi $N \subset X_{1} \oplus \oplus_{i \notin \Gamma} Y_{i}=X \cong M$.

Selanjutnya, $R$-modul injektif-lemah ekuivalen dengan $R$-modul rapat dimana ring $R$ merupakan ring q.f.d.

Teorema 4. Jika $R$ ring q.f.d, maka setiap $R$-modul rapat adalah $R$-modul injektif-lemah.

Dengan memanfaatkan Teorema 4, Teorema 3 dapat diperluas menjadi teorema berikut.

Teorema5. Untuk ring kanan $R$, kondisi berikut ekuivalen:

(i) ring $R$ adalah ring q.f.d kanan;

(ii) setiap jumlah langsung dari $R$-modul injektif kanan adalah injektif-lemah;

(iii) setiap jumlah langsung dari $R$-modul injektif

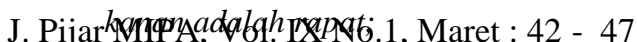

(iv) setiap jumlah langsung dari $R$-modul rapat adalah rapat;

(v) setiap jumlah langsung dari $R$-modul injektiflemah kanan adalah rapat; 
(vi) setiap jumlah langsung dari $R$-modul injektiflemah kanan adalah $R$-rapat; dan

(vii) setiap jumlah langsung dari injektif kanan $R$ modul yang tidak dapat dikomposisikan adalah $R$-rapat.

\subsection{Modul Mininjektif}

Jika $R$ ring, suatu $R$-modul $Q$ disebut modul mininjektif jika untuk setiap homomorfisma dari $f$ : $K \rightarrow Q$ dengan $K$ ideal sederhana dari $R$, terdapat homomorfisma $\varphi: R \rightarrow Q$ sedemikian hingga $f=\varphi i$. Setiap modul injektif adalah modul mininjektif. Sifat dasar dari mininjektif modul diberikan teorema berikut.

Teorema 6.Misalkan $Q$ adalah $R$-modul dan $Q=$ $Q_{1} \oplus Q_{2}$. Maka

1. modul $M$ adalah mininjektif jika dan hanya jika setiap $M_{i}$ adalah mininjektif,

2. jika $M$ adalah mininjektif lemah, maka setiap $M_{i}$ juga mininjektif lemah.

Suatu $R$-modul $N$ disebut modul $M$-mininjektif jika untuk setiap homomorfisma $f: X \rightarrow N$ dengan $X$ submodul $M$-siklik sederhana dari $M$, terdapat homomorfisma dari $\varphi: M \rightarrow N$ sedemikian hingga $f=\varphi i$. Jika $N$ adalah modul dengan socle nol, maka $N$ adalah $M$-mininjektif. Lebih lanjut, jika $M$ memiliki radikal nol, maka setiap $R$-modul $N$ adalah $M$-mininjektif. Karakterisasi dasar dari modul mininjektif diberikan dalam teorema-teorema berikut.

Teorema 7.Misalkan $M$ dan $N$ adalah $R$-modul.

1. Jika $N$ adalah $M$-mininjektif, maka $N$ adalah $X$ mininjektif untuk setiapsubmodul $M$-siklik $X$ dari M.

2. Jika $N$ adalah $M$-mininjektif dan $X \simeq N$, maka $X$ adalah $M$-mininjektif.

Teorema 8. Misalkan $M$ adalah $R$-modul dan $N$ adalah modul $M$-mininjektif. Jika $N$ esensial di modul $K$, maka $K$ juga modul $M$-mininjektif.

Seperti halnya pada modul injektif dan modul injektif-lemah, jumlahan berhingga dari keluarga modul mininjektif juga merupakan modul mininjektif, tetapi pada modul mininjektif jumlahan tak berhingga keluarga modul mininjektif juga merupakan modul mininjektif untuk sebarang ring.

Teorema 9. Misalkan $M$ adalah $R$-modul dan $\left\{N_{i} \mid i \in I\right\}$ adalah keluarga dari $M$-mininjektif modul. Maka $\prod_{i \in I} N_{i}$ adalah $M$-mininjektif.

Bukti. Misalkan $\varphi: s(M) \rightarrow \prod_{i \in I} N_{i}$ adalah homomorfisma dengan $s \in S=\operatorname{End}_{R}(M)$ dan $s(M)$ sederhana. Maka $\phi_{i} \varphi$ adalah homomorfisma dari $s(M)$ ke $N_{i}$ untuk setiap $i \in I$. Dari hipotesis yang diberikan dan definisi dari produk, terdapat $\hat{\varphi}: M \rightarrow$ $\prod_{i \in I} N_{i}$. Jadi $\prod_{i \in I} N_{i}$ adalah modul $M$-mininjektif.

Teorema 10. Jumlahan langsung dari modul-modul $M$-mininjektif adalah $M$-mininjektif.

Bukti. Misalkan $\varphi: s(M) \rightarrow \bigoplus_{i \in I} N_{i}$ dengans $\in S=$ $\operatorname{End}_{R}(M), s(M)$ adalah sederhana setiap $N_{i}$ adalah $M$-mininjektif. Karena $\varphi s(M)$ sederhana, maka $\varphi s(M)$ termuat dalam jumlahan berhingga $\bigoplus_{i \in I_{0}} N_{i}$, dimana $I_{0}$ adalah subset berhingga dari $I$. Dengan menggunakan Teorema 9, dapat ditemukan suatuhomomorfisma $\hat{\varphi}: M \rightarrow \bigoplus_{i \in I_{0}} N_{i}$. Jadi $\bigoplus_{i \in I} N_{i}$ adalah modul $M$-mininjektif.

\section{KESIMPULAN}

Hasil kali langsung atau jumlahan berhingga (direct product) dari keluarga $R$-modul injektif juga merupakan $R$-modul injektif. Ini juga berlaku untuk jumlahan berhingga dari keluarga $R$-modul injektiflemah dan $R$-modul mininjektif. Untuk jumlahan tak berhingga (direct sum) dari keluarga $R$-modul injektif belum tentu merupakan modul injektif. Tetapi jika $R$ adalah ring Noetherian, maka untuk sebarang keluarga $R$-modul injektif jumalahan tak berhingganya juga merupakan $R$-modul injektif. Begitu juga untuk jumlahan tak berhingga dari keluarga $R$-modul injektiflemah belum tentu merupakan modul injektif-lemah. Tetapi jika $R$ adalah ring q.f.d, maka untuk sebarang keluarga $R$-modul injektif-lemah jumalahan tak berhingganya juga merupakan $R$-modul injektif-lemah. Berbeda dengan $R$-modul injektif dan $R$-modul injektiflemah, jumlahan tak berhingga dari keluarga $R$-modul mininjektif merupakan $R$-modul mininjektif untuk sebarang ring $R$.

\section{DAFTAR RUJUKAN}

[1] Adkins, W.A and Weintraub,S.H., Algebra, An Aproach via Module Theory, Springer Verlag,New York, 1992.

[2] Fuller, A., Rings and Categories of Modules, Springer-Verlag Berlin Heidelberg, New York, 1992.

[3] Hazewinkel et al, Algebras, Rings and Modules, Kluwer Academics Publishers, New York, 2004.

[4] Wisbauer, R., Foundation of Modul and Ring Theory, Gordon and Breach, 1991.

[5] Jain, S.K and Lopez-Permouth, S.R., A Survey on the Theory of Weakly-Injective Modules, Computational Algebra, Marcel Dekker. 205232.

[6] Nicholson, W.K. and Yousif, M.F., Quasi-Frobenius Rings, Cambridge University Press, 2003.

[7] Nicholson, W.K., Mininjective Rings, Journal of Algebra 187, 548-579 (1997).

[8] Harada, Manabu, Self-Miniinjekctive Rings, Osaka J. Math, 19 (1982), 587-597 